\title{
LA MONEDA DE PLATA EN CASTILIA DURANTE LA PRIMERA MTTAD DEL SIGLO XVII
}

\author{
por \\ JOSE IGNACIO ANDRES UCENDO \\ Universidad del País Vasco ${ }^{1}$.
}

RESUMEN: Este articulo estudia las causas de la estabilidad de la moneda de plata castellana durante el siglo XVII. Su tesis principal es la siguiente: la estabilidad del real fue defendida por la Monarquía, a quien una devaluación bubiera perjudicado por causas fiscales. Asimismo, la burguesia comercial sevillana también se opuso a los planes de devaluación porque éstos perjudicaban una de sus principales actividades: la importación de meriancias extranjeras.

PALABRAS ClAve: Castilla. Moneda de plata. Siglo XVII.

ABSTRACT: One of the most important features of the Castilian silver currency (the famous (reals) during the seventeenth century was its stability. This article studies the two main causes of this fact. First the monarcby opposed any devaluation because of its consequences on the fiscal system, and second, it was joined in this attitude by the commerial bourgeoisie of Seville, for whom devaluation would be detrimental to one of their principal activies at this time: the import trade.

KEY wORDS: Monetary Policy. Castile. XVIth Century

\section{INTRODUCCION}

Uno de los rasgos más sorprendentes de la moneda castellana en el siglo XVII lo constituye la estabilidad del famoso real de plata. A diferencia de lo sucedido con el maravedi, tan afectado por las manipulaciones durante la centuria, y con las divisas de otros estados europeos, sometidas a una constante

1 Deseo agradecer a Emiliano Fernández de Pinedo, Isabel Mugartegui Eguía y Santiago Piquero Zarauz las sugerencias que me han permitido realizar este artículo. Por supuesto, cualquier defecto de las presentes líneas es de mi exclusiva responsabilidad.

Hicpania, LIX/2, num. 202 (1999) $533-545$ 
merma de su contenido metálico ${ }^{2}$, el real conservó las características establecidas por los Reyes Católicos el año 1497 en la pragmática de Medina del Campo, que reorganizaba el numerario castellano tras el desorden de la Baja Edad Media $^{3}$. Esto significaba que el real se hallaba en desequilibrio tanto respecto de los denás componentes del sistema monetario castellano como de las monedas extranjeras, lo cual provocó la aparición de los premios y ayudó al crecimiento de los desequilibrios comerciales.

Pese a su importancia, captada por algunos de sus contemporáneos como Cardona o Carranza, este hecho ha sido ignorado en los escritos sobre el tema, más interesados en las vicisitudes del vellón. Con todo, hay algunas excepciones entre las cuales cabe destacar los trabajos ya clásicos de Carreta Pujal y Hamilton así como los artículos más recientes de Vilar y Motomura, que se citan en la bibliografía.

La finalidad de las siguientes líneas es describir las consecuencias de la estabilidad del real sobre la economía castellana. Su contenido se divide en tres partes. La primera estudia la moneda de plata atendiendo a su particular posición en el sistema monetario castellano y en el contexto europeo. Ya en el siglo XVI habían circulado los primeros memoriales donde se proponía la devaluación del real, solicitud que proporcionó el argumento a multitud de peticiones, tratados y cartas fechados en las décadas iniciales del siglo XVII. Así, la segunda parte del artículo se dedica a describir los razonamientos de los partidarios de la devaluación y los de sus detractores. Como es bien sabido, triunfaron estos últimos. En las conclusiones explicaremos con detalle la causa de su victoria: la devaluación atacaba directamente a los intereses de la burguesía importadora y a los de la Corona.

\section{LA ESTABIIIDAD DE LA MONEDA DE PLATA}

¿Cuáles eran las principales características del real de plata? Según lo decretado en la pragmática de Medina del Campo, de un marco de plata de 230 grs de peso, con una ley de 11 dineros y 4 granos (algo más del 93\%) se debian obtener 67 reales, lo cual significaba que cada pieza pesaba 3,43 grs, con un contenido argénteo de 3,18 4 . Por lo general, el real se labraba en piezas de medio, 1, 2 y, sobre todo 4 y 8 reales, cuyos rasgos se resumen en la tabla adjunta:

2 Braudis, Ferdinard, «Los precios en Europa desde 1.450 hasta 1750»: Historia económica de Europa de la Universidad de Cambridge, Vol 5, Madrid 1977, págs 542-3.

3 Hamidon, Earl, El tesoro americano y la revolución de las precios, Madrid 1975, primcra edición en castellano, págs 61 y sigs.

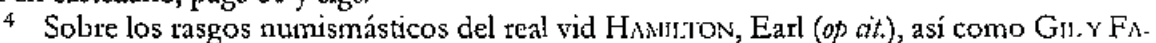

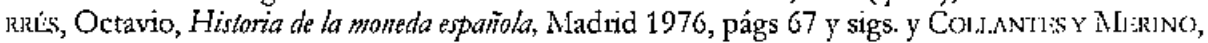
«Alteraciones al sistema monetario en Castilla durante el reinado de Carlos II\%: Cuadernos de Investigación Histónica, 1, (1977), págs 74-5.

Mapunis, LIX/2, núm. 202 (1999) 533-545 


\begin{tabular}{||l|c|c|c|c||}
\hline \multicolumn{1}{|c|}{ NOMBRE } & EQUIV. & PESO & LEY & GRS. AG. \\
\hline Real de a 8 & $272 \mathrm{mrs}$ & $27,4 \mathrm{gr}$ & $93,06 \%$ & $25,4 \mathrm{gr}$ \\
\hline Real de a 4 & $136 \mathrm{mrs}$ & $13,7 \mathrm{gr}$ & $93,06 \%$ & $12,7 \mathrm{gr}$ \\
\hline Reai de a 2 & $68 \mathrm{mrs}$ & $6,8 \mathrm{gr}$ & $93,06 \%$ & $6,3 \mathrm{gr}$ \\
\hline Real de a 1 & $34 \mathrm{mrs}$ & $3,4 \mathrm{gr}$ & $93,06 \%$ & $3,18 \mathrm{gr}$ \\
\hline Medio Real & $17 \mathrm{mrs}$ & $1,7 \mathrm{gr}$ & $93,06 \%$ & $1,58 \mathrm{gr}$ \\
\hline
\end{tabular}

EQUIV = equivalencia en mes. GRS $A G=$ contenido on plata. Calculado a partir de los datos de I Itwm:TON (Op tin), págs 61y sigs, Gus y liskres (Op cin), págs. 67 y sigs.

Con el propósito de trazar una relación estable entre las piezas de plata y cobre se ordenó que cada real equivaliese a $34 \mathrm{mrs}$. En dicha cifra apenas había 1,7 gis de plata, algo más de la mitad del contenido metálico del real, pero a este valor habia que añadir el del trabajo incorporado en la elaboración del maravedí, así como el pequeño beneficio obtenido por la Corona en su acuñación ${ }^{5}$. De esta forma, la pragmática resolvía uno de los problemas más frecuentes en los sistemas monetarios compuestos por distintos metales (en el caso castellano oro, plata y cobre): el de fijar las relaciones entre sus componentes.

Sin embargo, las frecuentes emisiones de vellón de escaso valor intrínseco durante los primeros años del siglo XVII hicieron imposible mantener la equivalencia anterior ${ }^{6}$. Como resultado de ellas, la moneda de cobre recibía un valor facial muy superior al de su contenido intrínseco. Dado que la plata se hallaba subvalorada en relación con el cobre ${ }^{7}$, se produjo su desaparición y entró en acción la célebre ley de Gresham. La cotización oficial de los reales resultaba inferior a la del mercado, y sus propietarios los guardaban celosamente o los dedicaban al comercio exterior. Apenas nadie estaba dispuesto a desprenderse de 1 real de plata por $34 \mathrm{mrs}$ de cobre puro si no se le concedia una prima adicional. De esta manera nacieron los célebres premios de la plata, que tanto obstaculizaron el desarrollo de la economía del reino durante la centuria.

Para contener el agio dentro de límites aceptables la Monarquía recurrió a las tasas ". Por una pragmática del 8 de marzo de 1625 se estableció que la reducción de cobre a plata se hiciera con un $10 \%$ de premio, cosa que no servía de nada cuando, según vatios miembros del Consejo de Hacienda, las reducciones se hacían en el mercado a un $50 \%$. La situación empeoró, además, por-

5 MarinNs, Juan, Tratado sobre la moneda de vellon, 1609, Edición del Instituto de Estudios Fiscales a cargo de Lucas Beitrán, pág. 44.

6 La lista de estas alteraciones se halla en HamlitTon, Earl, (op cit), págs 88 y sigs.

7 Sobre este asunto, vid GlassmaN, Debra y RfidisI, Angela, «Currency Depreciation in Early Modern England and Francen: Explorations in Economic History, ${ }^{\circ} 25$, (1988), págs 75-97.

\& Archivo General de Simancas (A.G.S de aquí en adelante), Consejo y Juntas de Hacienda (C.J.H en adelante), leg. 622.

AG.S,C.J.H, leg. 621 . 
que habia varias clases de premios. En 1628, por ejemplo, se contaban nada menos que 4: 3 de ellos legales y uno ilegal. Los primeros consistían en el agio del $10 \%$ tasado por la ley, así como el del $32 \%$ autorizado a las Diputaciones para el consumo del vellón y el que corría a cargo del factor general, Bartolomé Spinola, en sus tratos con los genoveses. En cuanto al ilegal, éste no era otro que el fijado espontáneamente por el mercado ${ }^{10}$.

Hasta aquí nos hemos ocupado de estudiar el real en relación con la moneda de cobre, lo cual nos ha permitido comprobar la existencia de uno de los dos desequilibrios mencionados al principio. A continuación nos referiremos al segundo, al desequilibrio existente entre el real de plata castellano y las demás monedas extranjeras.

Como es bien sabido, los estados europeos devaluaron con mucha frecuencia sus monedas durante los siglos de la Edad Moderna. Entre 1514 y 1666 la moneda de plata francesa perdió nada menos que el $66 \%$ de su contenido argénteo, mientras que entre 1620 y 1700 el argento de la lira genovesa se tedujo un $30 \%$ y el de su homónima milanesa un $20 \%$. No fueron muy distintas las cosas en el norte de Europa. De hacer caso a los datos expuestos por Cardona, la moneda holandesa soportó un descenso que llegaria al $44 \%$ de su valor intrínseco durante el período comprendido entre 1548 y 1622 . Asimismo, al comienzo de la Guerra de los 30 Años las monedas de varios estados alemanes y del centro-este de Europa soportaron graves devaluaciones, destacando la del denario muniqués, que perdió nada menos que el $75 \%$ de su plata, y la del "grosz» polaco, que sufrió una merma del $40 \% 11$.

Estos datos atestiguan lo particular del caso castellano, cuyo real mantuvo intacto su contenido metálico entre 1497 y 1721, si exceptuamos el período correspondiente a la breve devaluación de $1642^{12}$. Como resultado, se trataba de una moneda apreciada por encima de su nivel correcto, de suerte que, según Barbón y Castañeda, uno de los tratadistas que defendió con más vigor la devaluación del real:

10 A.G.S, C.J.H, leg. 643. Por supuesto, las tasas no pudieron cumplir sus objetivos, de suerte que la propia Corona se vió obligada a aumentar los premios oficiales. En junio de 1636 ya eran del $25 \%$ (C.J.H, leg. 750 ), cifra que en 1638 había crecido al $28 \%$ (A.G.S, C.J.H, leg. 806). Aquel mismo año Bartolomé Spinola recibió licencia para trocar al 30\% y en 1639 se aceptaron asientos con una reducción del $39 \%$, muy superior a la oficial. En todos los casos consultados sucedia lo mismo: los premios oficiales se rezagaban respecto de los vigentes en el mercado. Por este motivo, no faltaban los consejeros de hacienda que propusieran suprimir esas tasas y reconocer los premios del mercado.

11 Sobre los datos de la moneda francesa, ind. Glassman, Debra y Reidisi, Angela (op cit), págs 86 y 87. Acerca de las monedas de Milán y Génova, Cipol LA, Carlo, Mouvements Monétaires dans I Etat de Milan (1580-1700), París 1952, págs. 172 y sigs. En cuanto a la moneda holandesa, vid el memorial de Tomás de Cardona almacenado en la Biblioteca Nacional (B.N, de aqui en adelante), VE 13-29. Por último, las informaciones de las monedas alemanas y polacas se hallan en SuPp..., Barry "Currency and commerce in the early seventeeth century": Economic History R - $^{-}$ view (1957), págs. 248 y 249.

12 HAMiLTon, Earl (op cit), pág. 90.

/lippania, J.IX/2, núm. 202 (1999) 533-545 
«.. digo señor que se tome la cantidad y peso de nueve reales de plata de ley de nuestra moneda y se ajusta el peso della con otra tanta de la mejor moneda de otros Reynos, y hallaremos que seran diez reales y veinteisiete maravedis y medio los que ha de ajustar la valanza y el peso de los nueve ${ }^{13} .,{ }^{\prime}$

Esto significaba que el real estaba apreciado en un $20 \%$, porcentaje que en opinión de Carranza debía teducirse a un 12,5\%, cifra idéntica a la mencionada por el padre Mariana ${ }^{14}$. Puede que estas diferencias se deban a que Barbón escribía pensando en los pequeños estados del norte de Italia, mientras que el interés de Carranza se centraba, sobre todo, en Flandes y Francia, pero los dos testimonios reflejan, en lo fundamental, lo mismo: la apreciación de la moneda de plata castellana.

Es sabido que la apreciación de la divisa de un país encarece sus exportaciones y abarata sus importaciones, lo cual tiende a empeorar su balanza comercial, aunque pueda haber excepciones ${ }^{15}$. Si consideramos que el real era el medio de pago empleado en las transacciones exteriores podemos comprender mejor la creciente entrada de mercancías y géneros extranjeros, de la que existen abundantes testimonios en las obras de Moncada y González de Cellorigo, y que tanto dañó a la manufactura castellana. A esto se referían los partidarios más firmes de la devaluación cuando uno de ellos, Carranza, decía que:

«. dentro de sus provincias valgan mucho mas que en España los metales de oro i plata, a fin de que los españoles hagan sus empleos en ellas con el cebo de la ganacia $i$ de aver mas baratas las mercadurias con el maior valor que el oro i la plata alli tiene ${ }^{16 . . .}$ '

\section{LA DEVALUACION DEL REAI}

Conocedores de los problemas arriba indicados, numerosos escritores y tratadistas solicitaron durante los siglos XVI y XVII la devaluación del real. Los más famosos de todos fueron Cardona y Carranza, cuyas ideas influyeron en la breve devaluación de 1642 (conocida como el "crecimiento de la platas") ${ }^{17}$, aunque esta medida gozó del apoyo de más propagandistas. Sabemos, por ejemplo, que ya hacia 1530 se debatió en la Casa de la Moneda de Toledo ${ }^{18}$. Años des-

13 B.N., Raros y Especiales, C9, 28.

14 CARRANZA, Alonso de, El ajustamiento i proporcion de las monedas de oro, plata i cobre, 1629 , pág. 144 y MArlANA, Juan de (op cit), pág. 75.

15 Krugman, Paul y OBstreid, Maurice, Economia In ternacional, Madrid, 1993, págs. 375-y sigs.

16 CaruranzA, Alonso de (op cit), págs. 208-209. Vid también el contenido de la famosa proposición cardonista que abre las páginas del libro de Carranza, o BN, Manuscritos, 6731 291 y sigs. Otra elocuente muestra de lo que afirmamos se halla en una consulta del Consejo de Estado fechada en septiembre de 1607 (A.G.S, Estado, leg. 2.637).

17 HamLton, Earl (op cit). Vid. también, VII_AR BERRoGin, Juan, «Una pauta del pensamiento monetarista castellano: la proposición cardona", Moneda y Crédito (1978), págs. 449-459.

18 A.G.S, Diversos, $40-5$.

Hippania, LIX/2, núrn 202 (1999) 533-545 
pués, en 1587, Felipe II designó una Junta, ante la que se presentaron varios memoriales, para discutir de nuevo e l problema ". Finalmente, en los años 20 del siglo XVII destacaron las obras de Jerónimo de Ceballos, Pedro Castro y Guillén Barbón y Castañeda ${ }^{20}$.

Cardona y Carranza planeaban acuñar 84 reales por cada marco de plata en vez de los 67 tradicionales, aunque manteniendo la ley fijada en 1497. Esto significaba que el peso de cada pieza descendería de $3,43 \mathrm{gr}$ a $2,73 \mathrm{gr}$ y su contenido argénteo de 3,19 gr a 2,54 gr, lo cual representaba un envilecimiento del $26 \%$; prácticamente idéntico al marcado en el crecimiento de la plata de $1642^{21}$.

Entre los efectos positivos que tendría una devaluación del real merecen destacarse los siguientes:

En primer lugar, ayudaría a restablecer la proporción adecuada entre las piezas de plata y las de cobre ${ }^{22}$, rota por las manipulaciones del vellón. La razón de este hecho es fácil de comprender. Tras las alteraciones de la moneda de cobre resultaba imposible mantener la relación oficial entre el real y el maravedi. Según dijimos, el valor del trabajo incorporado en 34 mrs, más el de la pequeña cantidad de plata contenida en los mismos se equiparaba con el de un real argénteo. Pero esto no se podía hacer tras la expansión del vellón, pues en $34 \mathrm{mrs}$ de la depreciada moneda emitida, por ejemplo, en 1599 se almacenaba una cantidad de plata mucho menor que la de los anteriores $1,7 \mathrm{grs}$. Así, una solución, defendida por Cardona y Carranza, consistía en acuñar una moneda de plata con menor contenido argénteo, gracias a lo cual sería más fácil restablecer la perdida equivalencia. Esto también serviria para combatir los premios, tal y como se puede leer en el texto de una consulta de la Junta de Reformación:

«.. mientras la ley del trueco, tan desygual de lo que corre, siendo la plata el precio y medida de todas las mercadurias .. pues mientras no se ajustare en alguna manera la desproporcion del cobre con la plata, no sera posible tener execuxion, ni ygual medida, nada de quanto se resolviere en estas materias ${ }^{23} . . .1$

En segundo lugat, la devaluación obstaculizaría la salida de metales preciosos mejor que las tradicionales prohibiciones de sacas y registros, cuya eficacia era bastante pequeña ${ }^{24}$.

11) A.G.S, Diversos 1-31 y BN, Manuscritos, 6731-263 y sigs.

20 HAMIITON (op cit), pág 80 . Todavía podrían citarse más casos. En 1601 el adelantado de Castilla, alarmado ante la invasión de lienzos extranjeros, reclamaba una devaluación (A.G.S, Estado, leg 189). Carrera Pujal menciona un plan semejante en 1604 (vid. CARrCRA PLjAL, Jaime, Historia de la economía espanola, Barcelona 1943-7) y sabemos que este proyecto se revisó en 1621 ante la famosa Junta de Reformación (vid. GONZNLLEZ PAIS:NCI $\Lambda$, Angel, La Junta de Reformación, Valladolid 1934, pág. 137) y en 1624 ante la Junta de Comercio (A.G.S, Estado, leg. 2847).

21 HAMILTon, Earl, (op cib), págs. 80 y sigs.

22 Carranzs, Alonso de, (op cit), págs. 201 y sigs.

23 Citado por GONZALLEZ PALIENCI A, Angel, (op cit), pág. 525.

24 BN, Raros y Especiales, C9-28 y CARranzA Alonso de, (op cit), págs. 208 y sigs. Buena muestra de la ineficacia de estas leyes se halla en una consulta del Consejo de Hacienda fechada 
Pero la ventaja más importante residía en que la devaluación apoyaría con vigor a la manufactura castellana en su lucha contra la competencia extranjera. Esta posibilidad no pasó inadvertida a arbitristas como Moncada o Ceballos. En sus obras se defendían medidas que fomentasen la producción artesanal, y por eso comentaron favorablemente las propuestas de Cardona y Carranza. La devaluación encarecía el coste de las mercancías extranjeras, lo que abría una oportunidad a las nacionales ${ }^{25}$ pues, según se lee en un memorial de 1587:

«.. con esto los naturales se aplicaran al trabajo y sera ocasion de competencia entre ellos y los extranjeros ${ }^{26}$...

Estas eran las principales virtudes del «crecimiento de la plato». Sin embargo, alegaban sus detractores, varias dificultades desaconsejaban la adopción de esta medida.

En el caso de emitirse reales con menos contenido metálico, ¿qué sucedería con la moneda vieja, con más cantidad de plata?, ¿cuál de las dos se usaría en los pagos y transacciones cotidianas? ${ }^{27}$. Mas éste no era el principal defecto criticado por los partidarios de la estabilidad del real, que se esforzaron por convencer a las autoridades de lo impracticable de los planes de Cardona o Carranza con argumentos a los que eran muy sensibles. La devaluación, afirmaban, encarecería las importaciones e impulsaría el alza de precios en detrimento de las Rentas Reales. Además, no serviría para contener la salida de la plata hacia el exterior y, por último, obstaculizaría la contratación de nuevos asientos.

Según afirmaban los representantes de Sevilla ante las Cortes en 1609, la producción interna no podía atender la demanda casteliana de varios tipos de manufacturas y productos, lo cual significaba que una devaluación trababa el suministro de géneros vitales encareciéndolo ${ }^{2 \mathrm{k}}$. A fin de contener este encarecimiento, los defensores de la devaluación proyectaban imponer una tasa ${ }^{29}$. Para ello se apoyaban en una creencia bastante extendida en algunos sectores cuya expresión se halla en las obras de Moncada, González de Cellorigo o Fernández de Navarrete: Castilla atesoraba importantes riquezas naturales, de las que tenían urgente necesidad los extranjeros. Por esta causa, los comerciantes foráneos continuatían exportando hacia ella sus productos, incluso aunque sus precios se contuvieran con una tasa:

en marzo de 1634. En febrero de aquel mismo año habian llegado varios galeones de Tierra Firme con 8,5 millones de ducados en plata, de los cuales sólo se registraron 1,5. Lo demás entró, y probablemente salió, de contrabando. Vid. A.G.S, C.J.H, leg. 601.

${ }_{25} \mathrm{BN}$, Ratos y Especiales, VE 184-41. Vid. también BN, Manuscritos, 6731-32 y sigs.

26 BN, Manuscritos, 6731-251 y sigs.

27 BN, VE, Raros y Especiales, 206-17.

28 Actas de las Cortes de Castilla (A.C.C de aquí en adelante), vol. 25, págs. 448 y sigs.

25) BN, Manuscritos, 6731, 251-ss y VE 184-41. 
«. y alude a esta razon la necesidad que en todas partes tienen de muchas cosas de España, como son aceytes, lanas, corambres, especierias y otras menudencias, sin que no pueden pasar $\left.{ }^{30} ..\right)$

Sin embargo, los comerciantes sevillanos, seguidores de las opiniones tradicionales sobre el tema, no se dejaban engañat. En su opinión, los efectos de la tasa setían negativos, pues si:

«. los extranjeros no hallasen esta ganancia en sus mercaderias, que es la misma que asta aqui han tenido, es cosa verosimil que por no perderse en ellas no las traeran a España, de que resultara grandisima carestia en todas las mercadurias que hay en ella del mismo genero, y por consiguiente en los mantenimientos, porque supuesto que la abundancia o falta de las cosas es lo que les da o quita valor, si para el mucho gasto que hay en estos reinos y en los de Indias de alhajas y vestidos, no hay mas sedas, lienzos, paños y ottas mercadurias semejantes que las que se labran en España, fuerza es que tengan subidisimo precio ${ }^{31}$..»

Por tanto, la subida de precios, tan negativa para los rendimientos de las Rentas Reales, sería inevitable ${ }^{32}$. A esto había que añadir, además, la posibilidad de que los restantes estados europeos replicasen a una devaluación devaluando, en represalia, sus propias divisas ${ }^{33}$.

Uno de los problemas de la economía castellana consistía en la fuga de metales preciosos, provocada, aunque sólo en parte, por la apreciación del real castellano. Por este motivo, Cardona y Carranza creían que sus medidas serían un sólido dique contra la corriente que cada año sacaba fuera del reino crecientes cantidades de plata. Pero resultaba un error creer que la devaluación acabaría con ella. En realidad, la fuga de metales preciosos surgía de las importaciones de mercancías extranjeras y de los pagos de asientos y provisiones ${ }^{34}$.

Sabedor de esto, no extraña que Moncada, después de juzgar favorablemente el arbitrio de Cardona, lo calificara de:

30 BN, Manuscritos, 6731, 251-ss y 355 y sigs. Vid. también CARrAn7., Alonso de (op cit), pág 308. En ella Carranza afirmaba, despreciando por completo la importancia del contenido metálico en la fijación de los precios, que éstos no sufrirían ninguna subida pues los extranjeros se conformarian con percibir una moneda devaluada, con menos argento, sin que pasara nada:

«.. veremos sin duda como el mercader que aora vende sus marcadurias por reales de plata de treinta y quatro matavedis de sesenta y siete en marco, despues del ajustamiento se contentara con reales de menos peso e igual estimacion que los primeros.»"

31 A.C.C, vol. 25, pág. 451. Para un testimonio similar, redactado por otro sevillano, Ruy Fernández Pereira, vid. BN, Raros y Especiales, 190-6 y 190-7. Vid. tambiên MakınN^, Juan de (op cit), pág. 78 .

5 .

32 Vid. BN, VE 13-39 y Manuscritos 10441, 219-SS. Asimismo, A.G.S, Diversos, 40 -

33 MoNCADA, Sancho de, Restauración política de la abundancia de España, 1618. Edición del Instituto de Estudios Fiscales a cargo de Jean Vilar.

34 Mariana, Juan de (op cit), pág 79 y BN, Manuscritos, 10441, 223 y sigs.

Hitpania, LIX/2, nüm. $202(1999) 533-545$ 
«.. medio justificado, importante, pero no quita la raiz de donde nace la falta de moneda en España $\left.{ }^{35} ..\right)$

Si se quería acabar definitivamente con la huida de la plata era preciso, por un lado, terminar con los gravosos asientos y, por el otro, atacar las causas que favorecían los persistentes desequilibrios comerciales. La devaluación podía ser una eficaz ayuda para alcanzar ambos objetivos, pero debería formar parte de un conjunto de medidas orientadas al desarrollo de la manufactura castellana. Por este motivo el propio Cardona había concebido la idea de completar la devaluación con un sistema de estancos que ayudata a la producción artesanal ${ }^{36}$.

Otro problema impedía el éxito de los defensores de la devaluación. Según pensaban sus enemigos, ésta obstaculizaba la financiación de la ambiciosa política exterior castellana porque el tipo de cambio del real respecto de otras divisas europeas empeoratía a causa de su menor contenido metálico. La importancia de este último en la determinación de los trueques ya fue mencionada por el padre Mariana y el célebre Luis de Molina, en cuyo «Tratado sobre los cambios" se afirmaba que:

«.. en estos trueques ... se atiende a la cantidad de plata, comparandola con igual cantidad de plata o la cantidad de oro, comparandola con igual cantidad de oro de la misma pureza ${ }^{37} . . "$

Que estos principios no eran pura teoría, sino que resultaban familiares para los ministros de la Corona, obligados a respetarlos en sus tratos con los hombres de negocios, lo demuestran estas líneas procedentes de una consulta del Consejo de Estado, donde puede leerse que:

«.. los asientos que de aqui y de Italja se hizieren para aquellas provisiones, de razon se han de valuar conforme al valor intrinseco de la moneda que recivieren $\left.{ }^{38} ..\right)$

Por este motivo hay poco de extraño en que los críticos de Cardona y Carranza pronosticaran un empeoramiento de los cambios, pues:

«.. si V.M mandase labrar las dichas monedas .. todos en general confesaran que los cambios, las metcadurias, provisiones de armadas y bastimentos subiran de precio para sanear el daño ${ }^{39} ., p$

La tespuesta de Cardona y sus partidarios a estas objeciones tenía poco de original y consistía en la repetición de ideas expresadas en otros momentos. Ya

35 Moncada, Sancho (op cit), pág. 81 y Mariana, Juan de (op cit), pág. 79.

36 VIJ.AR, (op cit), pág. 456 y MONCADA, Sancho (op cit).

37 Motins, Luis de, Tratado sobre los cambios, 1597. Edición del Instituto de Estudios Fiscales a cargo de José Antonio Pérez Camacho, pág 61. Vid. también Marians, Juan de (op cit), pág. 78.

38 A.G.S, Estado, leg. 2045. 10441-219.

Sobre esto, vid. BN, VE 190-6, 195-2 y 207-66. Vid, también Manuscritos 6731-85 y

Hiqpania, LIX/2, núm. 202 (1999) 533-545 
Carranza, ignorando la importancia del contenido metálico en la fijación de los precios, había indicado que la devaluación no provocaría el encarecimiento de las mercaderías importadas, algo que, de producirse, se contendría con una tasa. El mismo razonamiento fue empleado para garantizar que no habría alteraciones en los cambios. La mejor expresión del mismo se halla, una vez más, en la obra de Carranza, quien afirmaba que los trueques dependían del valor facial de la moneda y que:

«.. los cambios .. solamente se deben regular por el valor corriente que los principes soberanos dan a las monedas en las tiertas de su imperio, que es al que se debe atender ${ }^{40}, .$,

Esta opinión era semejante a la defendida por Pedro de Miranda en un memorial de los últimos años del siglo XVI ${ }^{41}$ en el cual, tras defender como Cardona o Carranza que la devaluación no afectaría a los cambios, reclamaba el fortalecimiento de las tradicionales prohibiciones de saca y de la regulación de cambios, algo que ya a inicios de aquella centuria fuera rechazado por el padre Molina ${ }^{42}$.

\section{CONCLUSIONES}

Tras todo lo anterior queda clato que las consecuencias de una hipotética devaluación no sólo afectaban al sistema monetario del reino, sino también a su vida manufacturera, comercial y financiera. En cuanto a esta última, resulta difícil creer en las alegaciones de Cardona y Carranza, para quienes los cambios no sufrirían ningún empeoramiento y es más razonable suponer lo contrario. El descenso en el contenido metálico del real obstaculizaría la firma de nuevos asientos, lo cual tenía consecuencias nada favorables para la costosa política exterior castellana. Tal fue la razón alegada por Felipe II para rechazar la devaluación propuesta en $1587^{43}$. Asimismo, a inicios de 1643, poco antes de que una pragmática suprimiera el crecimiento de la plata realizado a fines del año antetior, este parecer era compartido por varios miembros del Consejo de Estado y dominaba en el de Hacienda, de suerte que en una consulta redactada el 14 de febrero podemos leer que:

«.. la real hacienda padeceria bastante si pasase adelante esta pregmatica .. por lo que a ocasionado y ocasionara a crecer los premios de las reducciones y alteracion de los cambios ${ }^{44}$..»

40 Carranza, Alonso de (op cit), pág. 318 y 314 . Vid. asimismo, BN, Ratos y Especiales 9-16 y $13-29$

41 BN, Manuscritos, 6731-349.

42 Moljn, Luis de (op cit), págs. 116-8.

43 A.G.S, Diversos, 1-30.

44 A.G.S, C.J.H, leg 855 . Vid. también los legs. 853 y 854 . En cuanto al Consejo de Estado, vid. A.G.S, Estado, leg. 2667.

Hipqania, LJX/2, núm. 202 (1999) 533-545 
Más complejo es calcular la incidencia de la devaluación sobre los precios. Son numerosos los testimonios que demuestran la gravedad de los desequilibrios comerciales causados por la creciente entrada de importaciones. En 1587, por ejemplo, se afirmaba que cada año entraban a través de Sevilla géneros por valor de 2,5 millones de ducados y apenas salían mercancias por valor de 300.000 , cifras idénticas a las mencionadas en una consulta sobre la carestía de las cosas leída años después ante la Junta de Reformación ${ }^{45}$. Por este motivo, uno de los fines confesados de la devaluación era ayudar a la manufactura castellana, lo cual sería, además, la mejor manera de combatir los desequilibrios comerciales. Pero esto presentaba un grave problema que puede resumirse en la siguiente pregunta: ¿ estaba la producción castellana preparada para cubrir el hueco de la extranjera? Varios indicios autorizan a creer que no. Esa era la opinión de los comerciantes sevillanos, atemorizados ante el incremento de precios que pronosticaban como fruto de la devaluación ${ }^{46}$. Considerando que Sevilla dependía en gran parte del comercio de importación para mantener sus tráficos con América, estos testimonios pueden parecer interesados. Sin embargo, coinciden, en lo principal, con otros procedentes de fuentes más objetivas, como la ya citada Junta de Reformación, que en agosto de 1627 citaba a la prohibición de entrada de las mercancías extranjeras de 1623 entre las razones del alza de precios ${ }^{47}$. Esto mismo era indicado claramente en unas anónimas "Advertencias para la prohibición de mercaderias extranjeras» donde se prevenía contra su veda absoluta ${ }^{48}$. Para demostratlo, su autor dividía las importaciones en tres grupos, cada uno de ellos con un trato aduanero distinto. Así, proponía gravar con elevados derechos las entradas de hilos y tejidos de oro, y la de torcidos y telas de seda, cuya fabricación se podía desarrollar inmediatamente en el reino. El segundo grupo estaba formado por los tejidos de lana, el cáñamo, la clavazón, la cuchillería, el cobre, los mástiles, el vidrio, los cueros, la cera y el papel. En relación con ellos proponía una etapa de derechos moderados que crecieran poco a poco, a medida que se desarrollase su manufactura en Castilla, de suerte que la producción local sustituyera progresivamente a la foránea. Finalmente, defendía que se facilitara la entrada de géneros imprescindibles como el lino y el latón, cuyo cultivo y fabricación no se podía realizar en el país.

Todo esto sugiere que la manufactura castellana no estaba preparada para satisfacer la demanda interna, por lo que una devaluación causaría la subida de los precios de las mercancías traidas de fuera, de las que no se podia prescindir;

45 GonZÁLIFz PA.IENCIA, (op cit), págs. 45 y sigs. Vid. también el dictamen de Juan de Hoces, recogido en la pág 176 , donde se afírmaba que los extranjeros no "sacan en mercaderias destos reynos el diezmo de lo que traen...)

4 A.G.S, C.J.H, leg. 602 y A C.C, vol. 25 , págs. 448 y sigs.

47 GonZález PALENClA, (op cit), pág. 536 y Dominguzz Ormz, Antonio, La Hacienda de Felipe IV, Madrid 1960.

48 BN, Raros y Especiales, C 12-8.

IIiphuna, LJX/2, núm. 202 (1999) 533-545 
de ahí la importancia que tenían para Moncada y Carranza las medidas de apoyo a la producción local ${ }^{49}$.

Considerando cuanto hemos afirmado hasta ahora se comprenden mejor las causas de la estabilidad del real castellano: era lo más conveniente para los intereses de la burguesía importadora (sevillana en especial) y la Corona. La devaluación danaba las finanzas reales y el comercio de importación sevillano, cuyo valor resultaba vital para el fisco porque éste obtenía de él importantes ingresos, bien directamente a través de los almojarifazgos $o$, indirectamente, mediante las alcabalas y millones y las demás rentas pagadas por Sevilla ${ }^{50}$. Por este motivo, no era nada fácil que la Corona adoptara medidas que obstaculizaran ese tráfico, pese a sus negativos efectos sobre la economía del reino, pues eso sería:

(c.. agraviar mucho a Sevilla en tiempo que deve ser muy favorecida y amaparada de V.M por la importancia de su conservacion y lo mucho que vale a la Real, $\mathrm{Ha}-$ cienda ${ }^{51} . . n$

Los perjudicados por esta elección fueron, como es fácil de suponer, los intereses manufactureros o artesanales, cuyos representantes votaban en las Cortes a favor de la devaluación o la apoyaban en sus memoriales y tratados ${ }^{52}$.

En conclusión, los numerosos proyectos de devaluación se estrellaron ante la resistencia de los importadores y la Corona. Si recordamos que éstos eran los grupos gracias a cuya influencia se había adoptado una política comercial que en nada favorecia a la manufactura local, puede concluirse afirmando que la estabilidad del real fue una muestra más del triunfo de la burguesía importadora

49 Lo mismo sucedía en otras áreas como Navarta. Por lo general, las medidas con que se obstaculizaban las importaciones despertaban la oposición del Viejo Reino, cuyos representantes decían que:

«. su sustento principal depende del libre abasto y comercio .. que de necesidad, los que residen en las montañas avian de desamparar la tierra, por quanto no se coxen frutos en ella,...) (A.G.S, Estado, 2638)

50 A lo largo de todo el siglo XVII Sevilla aportó cerca del $25 \%$ de lo recaudado por la Hacienda Real en concepto de millones. Calculado a partir de datos de elaboración propia. Vid. ANDués, José Ignacio, La fiscalidad en Castilla durante el siglo XVII: el servicio de millones, 1601-1700. Tesis Doctoral Inédita, Facultad de Filologia, Geografia e Historia de la Universidad del País Vasco. Vitoria, 1995.

51 A.G.S, Estado, 2636

52 Asi se explican las ácidas alusiones de Cardona a los importadores y hombres de negocios. Sobre los primeros decía (BN, Raros y Especiales, 184-41) que:

«... es de esperar que los naturales y leales vasallos de V.M acetaremos este aumento y ajus-

tamiento de la moneda, solamente contradicho ... de los estrangeros que habitan en estos

Reynos en correspondencias con otros de sus naciones .,"

Por lo que se refiere a los segundos, hablaba (BN, VE 13-29) de:

«... estrangeros interesados, y los que parcicipan en los aprovechamientos de los asientos, cambios y recambios y en la saca de plata y oro..s

Hiqpania, L.IX/2, núm. 202 (1999) 533-545 
y de la Monarquía en su lucha contra la burguesía artesanal y transformadora de ciudades como Segovia o Toledo ${ }^{53}$.

\section{BIBLIOGRAFIA}

ANDRÉS, José Ignacio, La Fisscalidad en Castilla durante el siglo XVII: el servicio de millones, 1601 . 1700, Tesis doctoral inédita, Facultad de Fibologia, Geagrafia e Historia de la Universidad del Pais Vasco, Vitoria 1995.

BRAUDEL, Ferdinard, «Los precios en Europa desde 1450 hasta 1750»: Historia Económica de la Universidad de Cambridge, vol. 5 Madrid 1977.

CARRANZA, Alonso de, El ajustamiento i proporción de las monedas de oro, plata i cobre, 1629.

CARRERA PUjAL, Jaime, Historia de la economia española, Bạtcelona 1943-1947.

CIPOLLA, Carlo, Mouvements Monétaires dans / Etat de Milan (1580-1700), Paris 1952.

COLI_ANTES, E. y MERINO, J. P, «Alteraciones al sistema monetario en Castilla durante el reinado de Carlos II»: Cuadernos de Investigación Histórica, n I, (1977), págs. 73-99.

DOMÍNGUEZ ORTIZ, Antonio, La Hacienda de Felipe $I V$, Madrid 1960.

FERNANDEZ DE PINEDO FERNÁNISEZ, Emiliano, "Structure économique et conflits sociaux: corporations et marchands dans la monarchie espagnole (XIII ${ }^{*}$ au XVIII ${ }^{\circ}$ siecles)m: Atti deIla Tredicesima Settimana di Studio, Istituto Internazionale di Storia Eionomica, F. Datini, Prato 1991, págs. 449-466.

GIL y FARRES, Octavio, Historia de la moneda española, Madrid 1976.

GLASSMAN, Debra y REDISH, Angela, «Currency Depreciation in Early Modern Europay: Explorations in Economic Histon, no ${ }^{\circ}$, (1988) págs. 75-97.

GONZÁLE'Z PALENCIA, Angel, La Junta de Reformación, Valladolid 1934.

HAMILJ'ON, Earl, El tesoro amenicano y la resolución de los precios, Madrid 1975. Primera edición en castellano.

KRUGMAN, P Y OBSTFELD, M, Economia internacional, 1993 Madrid.

MARIANA, Juan de, Tratado de La moneda de vellón, 1.609. Edición del Instituto de Estudios Fiscales a cargo dé Lucas Beltrán.

MOLINA, Luis, Tratado sobre los cambios, 1597. Edición del Instituto de Estudios Fiscales a cargo de José Antonio Pérez Camacho.

MONCADA, Sancho de, Restauración politica de España, 1618. Edición del Instituto de Estudios Fiscales a cargo de Jean Vilat.

MOTOMURA, Akira, "The Best and Worst of Currencies: Seigniorage and Currency Policy in Spain, 1597-1650m: Thejoumal of Economic History, $\mathrm{n}^{\circ}$ 54, (1994), págs. 105-127.

PÉREZ, Joseph, La revolución de las comunidades de Castilla, Batcelona 1943-1947.

RuIZ MART'IN, Felipe, Los destinos de la plata americana, Madrid 1990.

SUPPIE, Barry, "Currency and commerce in the early seventeeth century»: Economic History Re" tiew, (1957), págs. 239-255.

VILAR BERROGAIN, Juan, «Una pauta del pensamiento monetarista castellano. La proposición Cardona, 1618-1628\%: Moneda y Crédito, 1978, págs 449-459.

53 Sobre este asunto, vid. FERníndoez de PINEdo FrRníndez, Emiliano, «Structure économique et conflits sociaux: corporations et marchands dans la monarchie espagnole (XIII' au XVII" siecles)m: Atti della (Tredicessima Settimana di Studion, Istituto Internazionale di Storia Economica F. Datini. Prato, 1991. Vid también Pirkez, Joseph, La revolución de las comunidades de Castilla, Barcelona 1979 .

Hispania, LIX/2, núm. 202 (1999) 533-545 